\title{
Pegylated Recombinant Human Arginase I BCT-100
}

National Cancer Institute

\section{Source}

National Cancer Institute. Pegylated Recombinant Human Arginase I BCT-100. NCI

Thesaurus. Code C88286.

A recombinant human arginase I (liver arg inase) covalently attached, via a succinamide propionic acid (SPA) linker, to a polyethylene glycol (PEG) of molecular weight 5,000 [rhArg-peg $(5,000 \mathrm{mw})]$ with potential antineoplastic activity. Upon intravenous administration of pegylated recombinant human arginase I BCT-100, arg inase metabolizes the amino acid arginine to ornithine and urea, depleting intracellular arginine, which may inhibit proliferation of cells that are auxotrophic for arginine such as hepatocellular carcinoma (HCC) cells. This agent may also work synergistically with various cytotoxic agents. 